\title{
Pemanfaatan Media Sosial dalam Public Relations di Sekolah Menengah Kejuruan
}

\author{
Prima Astri Wahyuni $^{1}$, Niken Febrina Ernungtyas ${ }^{2}$ \\ ${ }^{1,2}$ Public Relations, Sekolah Tinggi Ilmu Komunikasi Inter Studi \\ Email: primaaaws@gmail.com
}

\begin{abstract}
The problem in this study is the SMK Gema Gawita Tangerang which has decreased the number of prospective students. SMK Gema Gawita Tangerang must intensify its promotion and change the learning methods that have been carried out. This study aims to analyze the use of social media for public relations purposes that have been applied at SMK Gema Gawita Tangerang. This research uses a qualitative approach. There were 2 research informants from the school and were processed through transcripts from interviews. The results of this study indicate that the community prefers to communicate using social media managed by schools to provide information and obtain information to make it easier and more practical. Important findings in this study include 3 selective coding namely; Utilization of Social Media, Communicating with the Public, and Reactions Generated.
\end{abstract}

Keywords: Social Media, Public Relations, Vocational Schools

\begin{abstract}
Abstrak: Permasalahan dalam penelitian ini adalah SMK Gema Gawita Tangerang yang mengalami penurunan calon siswa/siswi. SMK Gema Gawita Tangerang harus menggencarkan promosinya dan mengubah metode pembelajaran yang telah dilakukan. Penelitian ini bertujuan untuk menganalisis penggunaan media sosial untuk keperluan hubungan masyarakat yang telah diterapkan di SMK Gema Gawita Tangerang. Penelitian ini menggunakan pendekatan kualitatif. Informan penelitian berjumlah 2 orang yang berasal dari pihak sekolah dan diolah melalui transkrip dari hasil wawancara. Hasil penelitian ini menunjukkan masyarakat lebih menyukai berkomunikasi menggunakan media sosial yang dikelola oleh sekolah untuk memberikan informasi dan mendapatkan informasi agar lebih mudah dan praktis. Temuan penting dalam penelitian ini diantaranya terdapat 3 selective coding yaitu; Pemanfaatan Media Sosial, Berkomunikasi dengan Publik, dan Reaksi yang Dihasilkan.
\end{abstract}

Kata Kunci: Media Sosial, Hubungan Masyarakat, Sekolah Kejuruan

\section{Pendahuluan}

"Media sosial telah menjadi platform penting dalam berbagai aspek kehidupan kita. Pada zaman sekarang, media sosial sudah mencakup hal yang luas seperti hiburan, pemasaran serta pembaruan berita-berita yang up to date" (Warner-Soderholm et al., 2018). "Media sosial memungkinkan masyarakat untuk menggunakan platform audio maupun video. Hal tersebut memiliki efek kehidupan yang lebih besar di zaman yang sudah canggih ini dibandingkan dengan konten tekstual sederhana" (Aparicio-Martinez et al., 2017).

Maka tidak mengherankan jika jejaring sosial seperti Facebook, Twitter, maupun Instagram mewakili salah satu bentuk interaksi sosial-budaya yang paling umum, khususnya untuk remaja. Saat ini para remaja menggunakan jejaring sosial untuk mempertahankan kontak tidak hanya dengan kerabat dekat, tetapi juga dengan kerabat yang memiliki jarak tempuh yang jauh. Semua media sosial mendorong penggunanya untuk berpartisipasi dan memberikan umpan balik terhadap suatu pesan atau 


\section{Jurnal Komunikasi Nusantara}

E-ISSN. 2685-7650

Vol. 2 No. 1 (2020), pp 10-16

DOI: https://doi.org/10.33366/jkn. v2i1.35

konten di media sosial. Pesan yang dikirimkan dapat diterima atau dibaca oleh banyak orang. Sebagian besar media sosial memberikan kesempatan bagi penggunanya untuk memberikan komentar, melakukan voting, berbagi informasi, dan lain-lain.

Usia adalah faktor penting yang menentukan perbedaan dalam penggunaan media sosial atau internet. Menurut penelitian yang dilakukan We Are Social, perusahaan media asal Inggris yang bekerja sama dengan Hootsuite, rata-rata orang Indonesia menghabiskan 3 jam 23 menit sehari untuk mengakses media sosial. Sebanyak 120 juta orang Indonesia menggunakan perangkat mobile, seperti smartphone atau tablet untuk mengakses media sosial, dengan penetrasi 45 persen. Dalam sepekan, aktivitas online di media sosial melalui smartphone mencapai 37 persen. Berdasarkan data, aplikasi yang paling sering digunakan oleh masyarakat, yaitu WhatsApp, Facebook, Instagram, dan yang terakhir adalah Line.

Penelitian ini menggunakan acuan dari Romanian Journal of Communication and Public Relations yang berjudul Facebook and Public Relations in Higher Education. A Case Study of Selected Faculties from the Czech Republic and Slovakia. Dalam jurnal acuan sebelumnya, peneliti meneliti Universitas yang ada di Slovakia, hasil penelitiannya yaitu, pertama, studi ini secara khusus berfokus pada fakultas-fakultas pendidikan dari dua negara.

Penelitian lebih lanjut dengan peningkatan ukuran sampel yang diperlukan. Kedua, data di peroleh melalui convenience sampling, yang dapat diterima untuk studi penjelasan. Ketiga, data menggunakan Power BI dan Netvizz di Juli 2018 diperoleh hanya dari media sosial Facebook. Namun demikian, beberapa perbedaan kecil dalam data berada di luar kontrol para peneliti. Data tentang jumlah pelamar dan siswa yang terdaftar tidak selalu rendah tergantung dengan tingkat keterlibatan Lembaga Pendidikan dengan media sosial.

Penggunaan media sosial telah mengubah kegiatan komunikasi dan hubungan masyarakat suatu organisasi. Strategi komunikasi, pemantauan berkelanjutan, pertanggungjawaban dari tenaga atau tim ahli untuk memperbarui informasi di situs web dan membuat konten yang menyediakan informasi yang relevan kepada publik dan menyediakan kualitas yang menurut pengguna dapat di terima. Saat ini hal tersebut sebagai acuan komponen standar dari communication mix.

Untuk menjadi salah satu marketing tools yang digunakan dalam menarik konsumen maupun pelanggan, media sosial tidak boleh hanya bersifat konstan atau hanya diam saja, namun sosial media harus dapat mempunyai dimensi yang selalu aktif dan up to date dalam menampilkan profil, aplikasi yang ingin disharingkan, melakukan diskusi, dan interaksi dengan khalayak. Tidak hanya itu, topik yang dibahas pun harus dapat menarik perhatian.

"Meningkatkan kompetisi antar Sekolah Menengah Kejuruan (SMK) Swasta di Kota Tangerang (dalam bidang yang sama di tingkat nasional) dapat mempertinggi kebutuhan lembaga untuk memahami, mengelola, dan memanfaatkan posisi mereka dalam bidang pendidikan dan interaksi yang baik kepada publik" (Dennis et al. \& Voss \& Kumar, 2013). Hal ini termasuk dalam komunikasi terbuka dan hubungan dekat dengan siswa, staf, dan pemangku atau pemegang kepentingan mereka. Banyak sekolah di Indonesia, sudah mulai menerapkan keinginan pasar pada umumnya.

Termasuk dengan teknik dan aktivitas yang telah disepakati oleh lembaga terkait. Alat komunikasi yang digunakan pun sudah bermacam-macam, hal ini digunakan oleh lembaga pendidikan untuk menciptakan berbagai tingkatan koneksi antara organisasi dan publik. Artinya, cara penggunaan media sosial yang benar menjadi titik puncak suatu Sekolah atau Lembaga Pendidikan untuk mencapai komunikasi yang berharga dan efektif serta dapat diterima oleh masyarakat dengan baik. 


\section{Jurnal Komunikasi Nusantara}

E-ISSN. 2685-7650

Vol. 2 No. 1 (2020), pp 10-16

DOI: https://doi.org/10.33366/jkn. v2i1.35

Pertanyaan penelitian studi ini meneliti dampak komunikasi di media sosial pada keterlibatan publik, khususnya SMK Gema Gawita Tangerang, dan pertanyaan yang diajukan adalah:

Q1: Saluran komunikasi apa yang dianggap oleh siswa sesuai untuk menarik mereka belajar di sekolah? Q2: Bagaimana sekolah mengelola media sosial untuk dapat berkomunikasi dengan publik?

Q3: Apa jenis reaksi yang dihasilkan oleh sekolah saat aktif menggunakan media sosial?

\section{Metode Penelitian}

Peneliti menggunakan jenis penelitian kualitatif dengan metode studi kasus, karena dapat menganalisa dengan pengamatan langsung dan bersifat apa adanya, serta dapat memahami suatu peristiwa atau fenomena secara jelas. Informasi diperoleh dari proses wawancara mendalam dengan pihak terkait, observasi dan juga dokumen-dokumen resmi sebagai penunjang data. Pendekatan kualitatif juga memiliki beberapa karakteristik didalamnya (Bagong dan Sutinah, 2005:169)

Untuk memahami permasalahan dan bagaimana subjek menyelesaikan masalah inilah diperlukan informasi yang kaya dan analisis yang mendalam (Endah, 2011). Studi kasus dipilih karena metode ini mampu menggali masalah secara lebih mendalam di dalam kasus dan mampu dianalisis dengan lebih baik sehingga diperoleh kesimpulan yang lebih baik.

Penelitian kualitatif dengan metode studi kasus ditempuh oleh peneliti yang ingin lebih memahami sebuah kasus tertentu. Kasus ini menarik minat peneliti sehingga diperlukan penggalian data untuk memahaminya secara detail. Selain itu studi kasus sesuai untuk menjawab pertanyaan bagaimana peran manajerial public relations yang dilakukan bidang komunikasi Sekolah Menengah Kejuruan Gema Gawita Kota Tangerang tentang "Pemanfaatan Media Sosial dan Public Relations".

Objek penelitian ini adalah bidang komunikasi Pendidikan di Sekolah Menengah Kejuruan Gema Gawita Kota Tangerang sebagai sumber untuk data primer. Penelitian lapangan dilakukan mulai tanggal 23 November 2019 sampai dengan 30 November 2019. Selama berada di lokasi penelitian, yakni Bidang Komunikasi Pendidikan, penulis melakukan wawancara, observasi dan studi dokumen.

Wawancara dilakukan terhadap individu di bidang pemasaran dan social media publishing. Wawancara bertujuan untuk mengetahui hal-hal berikut ini yaitu, saluran komunikasi apa yang dianggap oleh siswa sesuai untuk menarik mereka belajar di sekolah, kedua yaitu bagaimana sekolah mengelola media sosial untuk dapat berkomunikasi dengan publik, dan yang terakhir yaitu apa jenis reaksi yang dihasilkan oleh sekolah saat aktif menggunakan media sosial.

Observasi dilakukan terhadap aktivitas terstruktur yang telah dilakukan atau yang sedang direncanakan tim dari pemasaran sekolah. Observasi bertujuan untuk melihat seperti apa yang dilakukan oleh tim promosi dalam mempersiapkan hal-hal terkait.

(Gray $(2009,2009))$ said that "An advantage of focus groups is that they allow for a variety of views to emerge, while group dynamics can often allow for the stimulation of new perspectives". The focus group approach was prepared on the basis of reviewed literature (e.g. Alalwan et al., 2017; Jurasko-va, Jurikova, \& Kocourek, 2015; Rutter, Roper, \& Lettice, 2016; Vendemia, 2017).

\section{Hasil dan Pembahasan}

Peneliti mendapatkan beberapa temuan yang dapat menggambarkan bagaimana hubungan media sosial dengan masyarakat di ruang lingkup SMK Gema Gawita Tangerang. Dari hasil wawancara dan observasi peneliti melakukan wawancara kepada 2 informan yang memiliki peran untuk mengelola social media publishing dalam sekolah tersebut. Berdasarkan penelitian yang telah dilakukan, temuan terdapat 3 selective coding yaitu; Pemanfaatan Media Sosial, Berkomunikasi dengan Publik, dan Reaksi yang Dihasilkan. 


\section{Jurnal Komunikasi Nusantara}

E-ISSN. 2685-7650

Vol. 2 No. 1 (2020), pp 10-16

DOI: https://doi.org/10.33366/jkn. v2i1.35

\section{Pemanfaatan Media Sosial}

Pada selective coding ini terdapat 2 axial yaitu Penggunaan Saluran Komunikasi dan Sosial Media Terpilih.

1. Penggunaan Saluran Komunikasi

Seluruh informan mengatakan bahwa saluran komunikasi yang digunakan oleh sekolah yaitu proyektor dan power point. Tetapi hal tersebut tidak efektif digunakan, karena siswa kurang memperhatikan apa yang dijelaskan oleh gurunya. Hal ini terkonfirmasi dari informan (AW) yang menyatakan: "Pas saya belajar disana saya menggunakan power point dulu dengan menggunakan proyektor lalu tidak efektif setelah itu di update lagi diperkembangkan lagi menjadi menggunakan Edmodo."

2. Sosial Media Terpilih

Berdasarkan data wawancara yang ada dapat menunjukkan bahwa seluruh informan menyatakan alasan mereka memilih sosial media yang lebih efektif digunakan pada saat belajar mengajar. Hal ini terkonfirmasi dari informan I yang menyatakan bahwa "dengan perkembangan zaman kita sudah mengenal whatsapp, mengenal Instagram, sudah mengenal segala media sosial yang menurut kita efektif itu ya jadi interaksi antara siswa makin erat dan ruang belajarnya semakin ada." Dan Informan II yang menyatakan bahwa "Media sosial jaman sekarang yang efektif itu Instagram sama twitter soalnya kalo yang lain tuh udah ga produktif sih"

\section{Berkomunikasi dengan Publik}

Pada selective coding ini terdapat 1 axial yaitu Keefektifan.

1. Keefektifan

Berdasarkan data wawancara yang ada dapat menunjukkan bahwa seluruh informan memberikan informasi tentang bagaimana sekolah berkomunikasi dengan publiknya. Informan I menyatakan bahwa media sosial Facebook menjadi jembatan untuk sekolah dan masyarakatnya berkomunikasi. Seperti yang informan katakan "kita menggunakan facebook, dari Facebook itulah kita banyak memberi interaksi rata-rata dari siswa smk gema gawita itu pasti menggunakan Facebook, di Facebook juga banyak updatean tentang lowongan pekerjaan terus juga banyak info tentang eventevent yang berlangsung terus juga banyak part time apabila siswa itu mau bekerja."

Sementara menurut informan II, sekolah kurang selektif dalam memilih media sosial, sehingga terjadi kekurangan informasi maupun komunikasi antara sekolah dengan masyarakat maupun siswa-siswinya. Seperti yang informan katakan "kalo dari pihak sekolah sih malah gaada yang mengelola ya pada saat jaman saya kemarin, malah kebanyakan siswanya, osisnya dan dari sekarang juga postingan terakhir yang saya lihat di media sosial sekolah saya agustus tahun ini itu kan udah lama banget kan ya jadinya ga berkembang media sosialnya jadinya kesannya ga keurus gitu."

\section{Reaksi yang Dihasilkan}

Pada selective coding ini terdapat 1 axial yaitu Keuntungan.

1. Keuntungan

Seluruh informan menyatakan bahwa dengan adanya kegiatan promosi yang dilakukan terus menerus melalui media sosial yang aktif, dapat menambah jumlah calon siswa baru setiap tahunnya. Seperti yang dikatakan oleh Informan I "kalo yang saya liat, setiap tahunnya jumlah siswa semakin meningkat ka, semakin meningkat karna mungkin dari siswanya atau osisnya giat promosi demi sekolahnya itu banyak siswanya.” Tidak jauh berbeda dengan yang dikatakan oleh 


\section{Jurnal Komunikasi Nusantara}

\section{E-ISSN. 2685-7650}

Vol. 2 No. 1 (2020), pp 10-16

DOI: https://doi.org/10.33366/jkn. v2i1.35

informan I, informan II menyatakan bahwa "dan yang terakhir saya lihat sekolahnya ada pembangunan infrastruktur dan siswanya yang makin banyak."

Tabel 1. Hasil Wawancara

\begin{tabular}{|c|c|}
\hline & Komunikasi apa yang dianggap oleh siswa sesuai untuk menarik mereka belajar di \\
\hline & $\begin{array}{l}\text { WhatsApp, } \\
\text { Instagram, } \\
\text { Twitter, } \\
\text { Facebook, } \\
\text { Edmodo, dan } \\
\text { Microsoft Power Point }\end{array}$ \\
\hline Bag & ana sekolah mengelola media sosial untuk dapat berkomunikasi dengan publik? \\
\hline & $\begin{array}{l}\text { Melakukan komunikasi melalui WhatsApp, } \\
\text { Melakukan komunikasi melalui Facebook, } \\
\text { Melakukan komunikasi melalui Edmodo, } \\
\text { Memberikan informasi tentang event-event yang akan berlangsung, } \\
\text { Memberikan informasi tentang lowongan pekerjaan, dan } \\
\text { Memberikan informasi tentang informasi umum yang up to date. }\end{array}$ \\
\hline Apa & nis reaksi yang dihasilkan oleh sekolah saat aktif menggunakan media sosial? \\
\hline & $\begin{array}{l}\text { Lebih yakin saat melakukan promosi sekolah, } \\
\text { Mendukung penuh OSIS saat ingin melakukan promosi, } \\
\text { Guru-guru ikut mendukung kegiatan yang akan dilakukan oleh OSIS, } \\
\text { Sekolah mendapatkan income dari sesuatu yang di upload ke media sosial, sehingga } \\
\text { OSIS maupun pihak sekolah mendapatkan pendapatan, dan } \\
\text { Dampak untuk sekolah yang tidak terlalu signifikan karena media sosial yang kurang } \\
\text { up to date. }\end{array}$ \\
\hline
\end{tabular}

Pada penelitian sebelumnya, website yang disajikan oleh sekolah adalah pilihan yang paling tepat untuk membuat siswa tertarik dalam kegiatan proses belajar mengajar. Kegiatan promosi yang dilakukan pun tidak efektif, karena yang lebih efektif adalah rekomendasi dari para alumni. Sementara temuan yang didapatkan oleh peneliti kali ini, saluran komunikasi yang di gunakan oleh SMK Gema Gawita Tangerang tidak efektif. Diperlukan pembaruan metode pembelajaran di sekolah yang dapat menarik minat belajar siswa/siswi. Media sosial yang paling di harapkan siswa agar bisa digunakan yaitu WhatsApp dan Instagram. Selain untuk metode pembelajaran, media sosial tersebut dapat digunakan untuk keperluan promosi sekolah agar sekolah tersebut lebih banyak di minati oleh calon siswa/siswi.

\section{Kesimpulan}

Media sosial adalah media online yang mendukung interaksi sosial serta menggunakan teknologi berbasis web yang mengubah komunikasi menjadi dialog interaktif. "Media sosial memungkinkan masyarakat untuk menggunakan platform audio maupun video. Hal tersebut memiliki efek kehidupan yang lebih besar di zaman yang sudah canggih ini dibandingkan dengan konten tekstual sederhana" (Aparicio-Martinez et al., 2017). Karena itu, media sosial dapat dilihat sebagai fasilitator online yang menguatkan hubungan antar pengguna sekaligus sebagai sebuah ikatan sosial. 


\section{Jurnal Komunikasi Nusantara}

E-ISSN. 2685-7650

Vol. 2 No. 1 (2020), pp 10-16

DOI: https://doi.org/10.33366/jkn. v2i1.35

Berdasarkan data yang telah ditemukan, media sosial sangat dibutuhkan oleh sekolah untuk melakukan promosi dan berinteraksi dengan masyarakat. Hal ini dapat berjalan dengan efektif jika media sosial dapat digunakan ataupun diolah dengan baik dan aktif. Seiring perkembangannya waktu, media sosial akan terus berkembang dan sangat dibutuhkan. Dampak yang didapatkan bisa secara langsung dirasakan oleh pihak sekolah maupun masyarakat. Jadi, media sosial yang digunakan dengan aktif akan dapat berguna bagi guru, siswa/siswi maupun wali murid dalam kegiatan belajar mengajar.

SMK Gema Gawita Tangerang harus berupaya lebih dalam meningkatkan komunikasi yang aktif dan efektif demi terciptanya hubungan yang baik dengan siswa/siswi nya maupun dengan orangtua/wali muridnya. Hal ini untuk mempertahankan sekaligus meningkatkan hubungan masyarakat dengan media sosial yang telah dikelola oleh pihak sekolah.

\section{Daftar Pustaka}

Eger, Ludvik., Egerova, Dana., Kryston, Miroslav. (2019). Facebook and Public Relations in Higher Education. Journal of Communications and Public Relations. 21, 7-30.

Alalwan, A. A. (2017). Social media in marketing: A review and analysis of the existing literature. Telematics and Informatics, 34, 1177-1190. https://doi.org/10.1016/j.tele.2017.05.008

Esquinsani, R. S. S., \& Esquinsani, V. A. (2017). The Choice of the School Manager in the Brazilian Public Networks: On the Concept of Democratic Management of Teaching. Creative Education, 8, 1424-1432. https://doi.org/10.4236/ce.2017.89100

Yilmaz, İ.G., Aygün, D. and Tanrikulu, Z. (2017). Social Media's Perspective on Industry 4.0: A Twitter Analysis. Social Networking, 6, 251-261. https://doi.org/10.4236/sn.2017.64017

Wahila, R., Mwape, L., Lyambai, K., \& Kabinga-Makukula, M. (2018). Use of Social Media to Support Nursing Students' Learning in Zambia. Creative Education, 9, 1237-1251. https://doi.org/10.4236/ce.2018.98092

Gu, Rui., Higa, Kunihoki., Moodie, Douglas R. (2011). A Study on Communication Media Selection: Comparing the Effectiveness of the Media Richness, Social Influence, and Media Fitness. Journal of Service Science and Management, 4, 291-299. https://doi:10.4236/jssm.2011.43035

Daka, H., Jacob, W.J., Kakupa, P. and Mwelwa, K. (2017). The Use of Social Networks in Curbing HIV in Higher Education Institutions: A Case Study of the University of Zambia. World Journal of AIDS, 7, 122-137. https://doi.org/10.4236/wja.2017.72011

Islam, S., \& Mahmood, M. I. (2018). A Qualitative Study on the Outcomes of Social Media Advertising. Advances in Journalism and Communication, 6, 61-73. https://doi.org/10.4236/ajc.2018.62006

Maweu, G. and Yudah, O.A. (2020). Utilization of Social Media Platforms among Information Science Students at University of Kabianga. Open Access Library Journal, 7: e6090. https://doi.org/10.4236/oalib.1106090

Arnbjörnsson, E. (2014). The Use of Social Media in Medical Education: A Literature Review. Creative Education, 5, 2057-2061. http://dx.doi.org/10.4236/ce.2014.524229

Safori, A. O., \& Rahman, N. A. B. A. (2019). Higher Education and Social Media: An Empirical Evidence from Jordan and Malaysia. Advances in Journalism and Communication, 7, 118-128. https://doi.org/10.4236/ajc.2019.74008

Chan, Chi Kin., \& Virkki, Johanna. (2014). Perspective for Sharing Personal Informations Online Social Networks. Social Networking, 3, 41-49. https://doi.org/10.4236/sn.2014.31005

Lint, Anna H. (2013). E-Learning Student Perceptions on Scholarly Persistence in the $21^{\text {st }}$ Century with Social Media in Higher Education. Creative Education, 4, 718-725. https://doi.org/10.4236/ce.2013.411102 


\section{Jurnal Komunikasi Nusantara}

E-ISSN. 2685-7650

Vol. 2 No. 1 (2020), pp 10-16

DOI: https://doi.org/10.33366/jkn. v2i1.35

Haryanto, Rudy. (2012). Pengembangan Strategi Pemasaran dan Manajemen Hubungan Masyarakat dalam Meningkatkan Peminat Layanan Pendidikan. Journal Economy and Business, 11, $27-$ 34.

Ikhwan, Afiful. (2018). Penerapan Manajemen Hubungan Sekolah dan Masyarakat dalam Perspektif Islam. Journal Of Islamic Education, 2, 1-16.

Ani, Andi Afrilliya. (2017). The Analysis of Public Relations Position within an Organization Structure and the Implication of its Role and Function in Various Organizations. Journal Social. 20, 2937. 